\title{
Person-related factors associated with work participation in employees with health problems: a systematic review
}

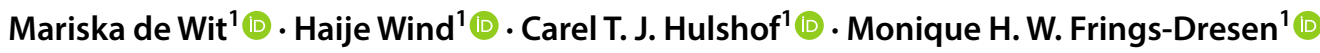

Received: 22 November 2017 / Accepted: 18 April 2018 / Published online: 26 April 2018

(c) The Author(s) 2018

\begin{abstract}
Purpose The objective of this systematic review was to explore and provide systematically assessed information about the association between person-related factors and work participation of people with health problems. The research question was: what is the association between selected person-related factors and work participation of workers with health problems? Methods A systematic review was carried out in PubMed and PsycINFO to search for original papers published between January 2007 and February 2017. The risk of bias of the studies included was assessed using quality assessment tools from the Joanna Briggs Institute. The quality of evidence was assessed using the GRADE framework for prognostic studies.

Results In total, 113 studies were included, all of which addressed the association between person-related factors and work participation. The factors positively associated with work participation were positive expectations regarding recovery or return to work, optimism, self-efficacy, motivation, feelings of control, and perceived health. The factors negatively associated with work participation were fear-avoidance beliefs, perceived work-relatedness of the health problem, and catastrophizing. Different coping strategies had a negative or a positive relationship with work participation.

Conclusions The results of this review provide more insight into the associations between different cognitions and perceptions and work participation. The results of this study suggest that person-related factors should be considered by occupationaland insurance physicians when they diagnose, evaluate or provide treatment to employees. Further research is required to determine how these physicians could obtain and apply such information and whether its application leads to a better quality of care.
\end{abstract}

Keywords Perceptions $\cdot$ Cognitions $\cdot$ Person-related factors $\cdot$ Work participation

\section{Introduction}

Sickness absence has negative financial consequences and leads to a loss of enthusiasm and satisfaction with the work situation (Sieurin et al. 2009). In addition, long-term sick leave can lead to lower self-confidence, a depressed mood and feelings of isolation (Bryngelson 2009; Vingård et al. 2004). These negative consequences of sick leave constitute

Electronic supplementary material The online version of this article (https://doi.org/10.1007/s00420-018-1308-5) contains supplementary material, which is available to authorized users.

Mariska de Wit

m.e.dewit@amc.uva.nl

1 Department Coronel Institute of Occupational Health, Academic Medical Center, University of Amsterdam, Amsterdam Public Health research institute, PO Box 22700, 1100 DE Amsterdam, The Netherlands significant reasons why it is important to minimize the work absence of employees due to health problems.

In order to minimize work absence and improve work participation, it is essential to know which factors influence work retention and return to work (RTW) after sick leave. Research has revealed that sick leave is determined by many different factors (Dekkers-Sánchez et al. 2013; World Health Organization 2001). In addition to disease-related and environmental factors, person-related factors such as cognitions and perceptions of employees also play a role in work participation (Dekkers-Sánchez et al. 2013; Iles et al. 2008; Vooijs et al. 2015). Research by Dekkers-Sánchez et al. (2013) has revealed that physicians identify person-related factors as important factors for RTW. The cognitions and perceptions of an employee about his or her health problems or limitations, are factors in which clinicians could intervene to encourage work participation (Dekkers-Sánchez et al. 2013; Verbeek 2006). 
As most research acknowledges the multifactorial nature of sick leave, many reviews have been conducted to gain better insight into the precise factors influencing the work participation of employees with health problems. However, most of these reviews are limited to specific diseases or disorders, or are limited to the outcome RTW rather than work participation in general (Blank et al. 2008; Clay et al. 2010; Van Velzen et al. 2009). In addition, as far as we know, there is no review which primarily focuses on the cognitions and perceptions of employees themselves that influence work participation. This is despite the fact that structuring the information about the influence of cognitions and perceptions could help to develop tailored interventions targeting these factors. Such interventions could in turn be used to support work participation of employees with health problems (Dekkers-Sánchez et al. 2013). Moreover, a clear overview of the association between person-related factors and work participation could assist occupational physicians and insurance physicians to prevent sick leave or decrease the duration of sick leave in these employees.

This systematic review was conducted to fill this gap in research and provide structured information about the association between person-related factors and work participation for employees with all kinds of diseases, disorders and injuries. For this review of the literature, we formulated the following research question using the patient, intervention, comparison, outcome (PICO) statement: in employees with health problems (P), which person-related factors (I) are associated with work retention and return to work after sick leave $(\mathrm{O})$ ?

\section{Methods}

The Preferred Reporting Items for Systematic Reviews and Meta-Analyses (PRISMA) guidelines were followed as a basis for reporting this systematic review (Moher et al. 2009). This review is registered in the Prospective Register of Systematic Reviews (PROSPERO 2017 registration number CRD42017062459; https://www.crd.york.ac.uk/PROSP $\mathrm{ERO} /$ ).

\section{Information sources and search strategy}

Literature searches were conducted by the first author in the databases PubMed and PsycINFO (MdW). The search strategy had three main elements: health problems, personrelated factors and work participation. The main personrelated factors of interest that formed the basis of our search strategy were selected by two experts in occupational and insurance medicine. The possible relevance of these factors for work participation was confirmed by a workgroup consisting of three insurance physicians, two occupational physicians and a patient representative. The broad term 'work participation' covered concepts such as RTW, sickness absence and current work status. The search strategies used in PubMed and PsycINFO are presented in Online Resource 1.

\section{Eligibility criteria}

This review includes studies published between January 2007 and February 2017 that investigated the association between person-related factors and work participation of employees with health problems. Articles considered eligible for inclusion had to be available in full-text in English or Dutch and had to be published in peer-reviewed journals. We included (non-)randomized controlled trials, cohort studies, cross-sectional studies and qualitative studies. Reference lists of meta-analyses and reviews that were found in our search were examined to identify additional publications, in order not to miss any relevant literature published between 2007 and 2017. Case studies were excluded from this review. Studies in which students, military personnel or veterans with health problems or employees with substance abuse problems were the subjects of the analyses were excluded. We also excluded studies in which disability was the only outcome, or studies in which it was not clear how the personrelated factors were measured.

\section{Study selection}

One reviewer selected all relevant studies on the basis of the title and abstract (MdW). The other researchers (HW, $\mathrm{CH}, \mathrm{MF}$ ) each screened the title and abstract of one-third of all studies, so that all studies were independently screened by two reviewers (MdW and $\mathrm{HW}, \mathrm{MdW}$ and $\mathrm{CH}$ or MdW and MF). Subsequently, the full-text articles of potentially relevant studies were reviewed by one reviewer to determine whether they fulfilled all the inclusion criteria (MdW). Additionally, three reviewers screened $10 \%$ of the full-text articles (HW, CH, MF). In the case of doubt, eligibility of the study was discussed until consensus was reached. Reasons for exclusion were documented.

\section{Extraction of data}

One reviewer extracted the details and findings of the studies included using a self-developed data-extraction form (MdW). Data-extraction from $30 \%$ of the studies was checked by the other three reviewers (HW, $\mathrm{CH}, \mathrm{MF}$ ). Disagreements about the data-extraction were resolved by discussion and consensus. The following details were extracted: number of subjects, age, gender, occupation and health status of subjects, study design, person-related factors of interest, time to follow-up and the main results. To ensure a clear overview of the main results, 
the coefficients and odds ratios were only noted in the table if they were significant and from multivariate analyses. In addition, we noted $p$-values from significant univariate analyses. Non-significant results were only described in words. We contacted authors when clarification of data was needed.

\section{Quality assessment}

The risk of bias of the studies included was assessed using quality assessment tools developed by the Joanna Briggs Institute (Joanna Briggs Institute 2014). Before the researchers assessed the risk of bias, the Joanna Briggs Institute criteria were discussed between the researchers in order to reduce ambiguity and disagreements between the researchers. One reviewer (MdW) assessed the risk of bias of all studies and the other reviewers (HW, CH, MF) each assessed the risk of bias of $10 \%$ of the studies. Disagreements were resolved by discussion and consensus. Each criterion from the quality tools was answered with 'yes', 'no', 'unclear' or 'not applicable'. For categorizing in studies with high, moderate and low risk of bias, we applied the same classification rules as used in the study by Reilly et al. (2016). Studies which met more than $80 \%$ of the criteria were considered as high-quality studies with a low risk of bias. Studies which met $50-80 \%$ of the criteria were considered as moderate-quality studies with a moderate risk of bias. Studies which met less than $50 \%$ of the criteria were considered as low-quality studies with a high risk of bias. Studies were not excluded on the basis of their risk of bias; however, the risk of bias was taken into account when drawing conclusions in this review.

\section{Grading the level of evidence}

The overall quality of evidence for the association between each person-related factor and work participation was assessed by one reviewer (MdW) using the Grading of Recommendations Assessment, Development and Evaluation (GRADE; Huguet et al. 2013) approach and discussed with the other reviewers (HW, CH, MF). The base level of the quality of evidence for the associations was based on the design and phase of the studies. The factors that were further examined were the risk of bias, inconsistency, indirectness, imprecision and publication bias. The overall quality of evidence for the associations was categorized as high, moderate, low or very low. If possible, a meta-analysis was performed to assess the effects of the person-related factors on work participation.

\section{Results}

\section{Studies selected}

In total, 3032 studies were found in PubMed and 1226 studies in PsycINFO (Fig. 1). After removing duplicates, studies without abstracts and books or book sections, 3465 studies remained. In total, 3226 studies were excluded after screening the title and abstract. The remaining 239 articles were reviewed on full text. Of these, 117 articles did not meet the inclusion criteria and were thus excluded. The reasons for excluding these articles were: (1) study group did not consist of employees; (2) participants did not have health problems at baseline; (3) factors of interest were not studied; (4) outcome of interest was not studied; (5) study method or results were not (clearly) described; or (6) other study type than (non-)randomized controlled trials, cohort studies, cross-sectional studies, qualitative studies, systematic reviews and meta-analyses. The remaining articles included 24 reviews and meta-analyses. After screening the reference lists of these studies, 15 studies were added, making a total of 113 studies that were included in this review. The characteristics of these studies are presented in the data-extraction tables in Online Resource 2.

\section{Risk of bias}

From the 113 studies included, 68 had a low risk of bias, one study had a high risk of bias and the remaining 44 studies were classified as having a moderate risk of bias. A frequent reason for risk of bias in qualitative studies was that information about the researcher and his possible influence on the study was lacking. Moreover, many cohort studies did not meet the criteria for complete follow-up. Scores on each criterion of the quality assessment tools can be found in Online Resource 3.

\section{Evidence for the influence of person-related factors on work participation}

Results of the multivariate analyses of the quantitative studies that were included in this literature review are summarized in Tables 1 and 2. If no multivariate analyses were performed in a study, conclusions about the association between the person-related factor and work participation were based on the univariate or bivariate analyses that were performed in that study (Denis 2015). Due to the heterogeneity in methods used to measure the person-related factors and outcomes and the heterogeneity in the statistical analyses performed, it was not possible to perform meta-analyses. The quality of evidence for the potential factors associated 
Fig. 1 Search flowchart

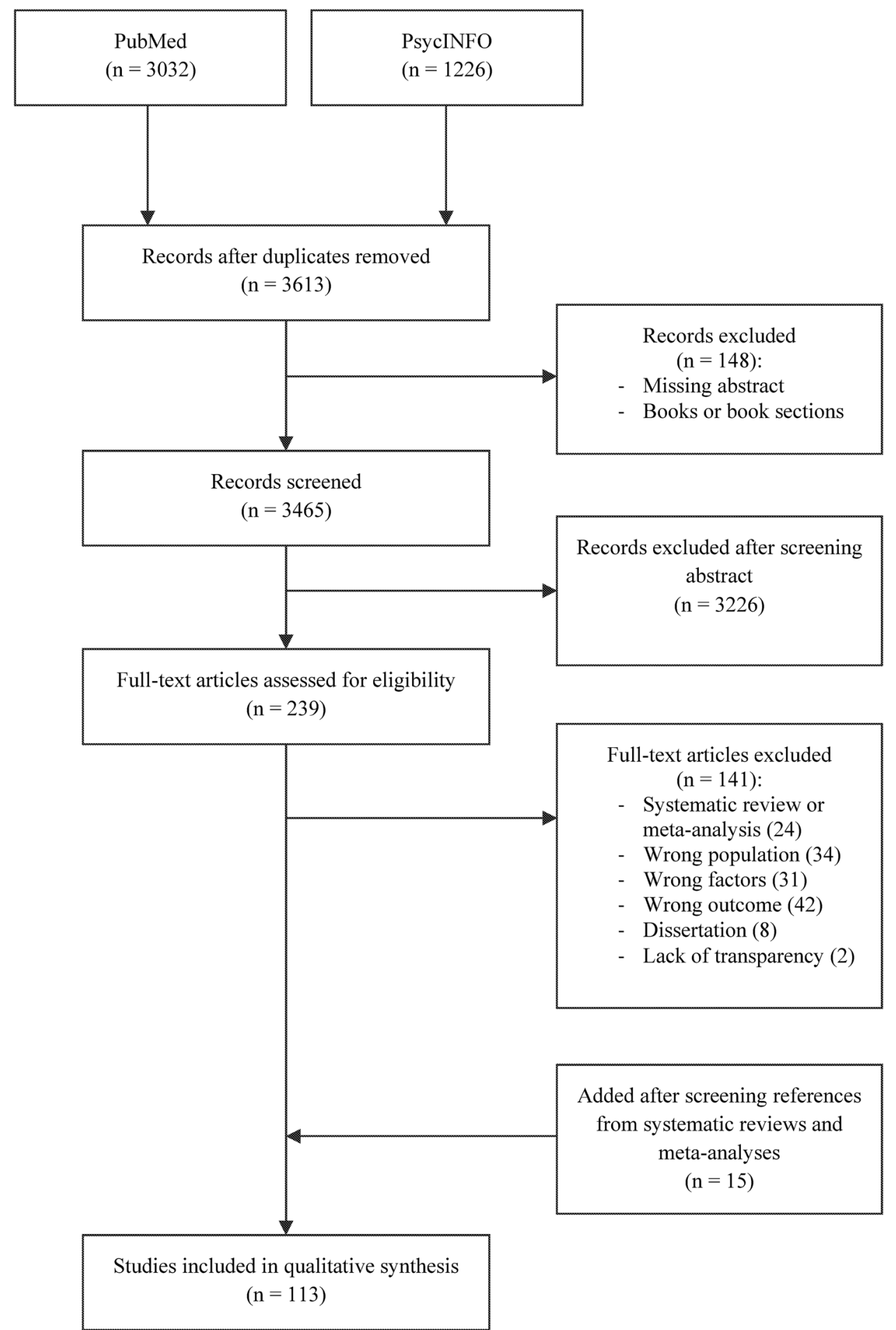

with work participation as assessed by GRADE is presented in Table 3. Because we used broad terms for the work participation outcomes and used strict inclusion criteria for the participants and the factors measured in the studies, none of the evidence was downgraded for indirectness. In addition, the criteria for publication bias were judged as not applicable, as the large body of evidence made it impossible to come to a conclusion on possible publication bias. Moreover, most of the studies were explorative and the phase of the investigation was already considered as a factor that could downgrade the quality of evidence. The synthesis of evidence led to a rating of moderate evidence for the association between the factors expectations regarding recovery or RTW and perceived health and work participation. The 
Table 1 Results of multivariate analyses of quantitative studies factors expectations, optimism, self-efficacy, motivation, feelings of control, and perceived health

\begin{tabular}{|c|c|c|c|}
\hline Factor & $\begin{array}{l}\text { Positive association } \\
+\end{array}$ & $\begin{array}{l}\text { Negative association } \\
\text { - }\end{array}$ & $\begin{array}{l}\text { No association } \\
0\end{array}$ \\
\hline $\begin{array}{l}\text { Positive RTW/recovery } \\
\text { expectations }\end{array}$ & $\begin{array}{l}\text { Audhoe et al. (2012) } \\
\text { Besen et al. (2015) } \\
\text { Busch et al. (2007) } \\
\text { Carriere et al. (2015a) } \\
\text { Carriere et al. (2015b) } \\
\text { Carstens et al. (2014) } \\
\text { Cowan et al. (2012) } \\
\text { Du Bois et al. (2009) } \\
\text { Ekberg et al. (2015) }{ }^{\text {a, }} \\
\text { Gross and Battié (2010) } \\
\text { Hou et al. (2012) } \\
\text { Hou et al. (2008) } \\
\text { Jensen et al. (2013) } \\
\text { Johansson et al. (2010) } \\
\text { Lindell et al. (2010) } \\
\text { Magnussen et al. (2007b) } \\
\text { Murgatroyd et al. (2016) } \\
\text { Opsahl et al. (2016) } \\
\text { Reme et al. (2009) } \\
\text { Richter et al. (2011) } \\
\text { Rönnberg et al. (2007) } \\
\text { Sampere et al. (2012) } \\
\text { Sluiter and Frings-Dresen (2008) } \\
\text { Spector et al. (2012) } \\
\text { Truchon et al. (2012) } \\
\text { Vuistiner et al. (2015) } \\
\text { Wåhlin et al. (2012) }\end{array}$ & & $\begin{array}{l}\text { Boot et al. (2008) } \\
\text { Coggon et al. (2013) } \\
\text { Ekberg et al. }(2015)^{\mathrm{a}} \\
\text { Gross and Battié }(2010)^{\mathrm{c}} \\
\text { Iakova et al. }(2012) \\
\text { Murgatroyd et al. }(2016)^{\mathrm{a}} \\
\text { Nieuwenhuijsen et al. }(2013)^{\mathrm{d}} \\
\text { Sluiter and Frings-Dresen }(2008)^{\mathbf{a}} \\
\text { Turner et al. (2008) } \\
\text { Wåhlin et al. }(2012)^{\mathbf{c}}\end{array}$ \\
\hline Optimism & $\begin{array}{l}\text { Hystad and Bye }(2012)^{\mathbf{a}, \mathbf{e}} \\
\text { Lydell et al. }(2011)^{\mathrm{b}, \mathrm{d}}\end{array}$ & & $\begin{array}{l}\text { Hystad and Bye }(2012)^{\mathbf{a}, \mathbf{e}} \\
\text { Øyeflaten et al. }(2008)\end{array}$ \\
\hline Self-efficacy & 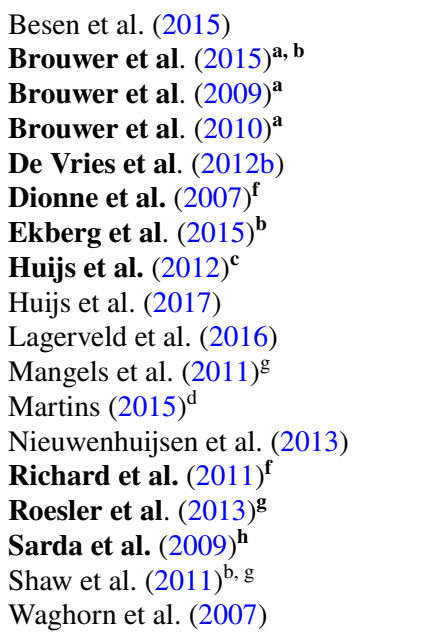 & Waynor et al. $(2016)^{\mathrm{a}}$ & $\begin{array}{l}\text { Brouwer et al. (2015) } \\
\text { Brouwer et al. }(2009)^{\mathbf{a}} \\
\text { Brouwer et al. (2010) } \\
\text { D'Amato and Zijlstra (2010) } \\
\text { Dionne et al. (2007) } \\
\text { Healey et al. (2011) } \\
\text { Huijs et al. (2012) } \\
\text { Murphy et al. (2011) } \\
\text { O'Sullivan et al. (2012) } \\
\text { Oyeflaten et al. (2008) } \\
\text { Richard et al. (2011) } \\
\text { Sampere et al. }(2012) \\
\text { Sarda et al. }(2009)^{\mathbf{h}} \\
\text { Strauser et al. (2010) } \\
\text { Stulemeijer et al. (2008) } \\
\text { Volker et al. (2015) } \\
\text { Wåhlin et al. (2012) } \\
\text { Waynor et al. (2016) }\end{array}$ \\
\hline Motivation & $\begin{array}{l}\text { Awang et al. (2016) } \\
\text { Boyle et al. }(2014)^{\mathbf{d}} \\
\text { Braathen et al. }(2007) \\
\text { Lydell et al. }(2011)^{\mathbf{b}, \mathrm{d}} \\
\text { Puolakka et al. }(2008)^{\mathbf{f}} \\
\text { Saperstein et al. }(2011)\end{array}$ & & $\begin{array}{l}\text { Elfving et al. }(2009)^{\mathbf{d}} \\
\text { Puolakka et al. }(2008)^{\mathbf{f}} \\
\text { Wan Kasim et al. }(2014)\end{array}$ \\
\hline
\end{tabular}


Table 1 (continued)

\begin{tabular}{|c|c|c|c|}
\hline Factor & $\begin{array}{l}\text { Positive association } \\
+\end{array}$ & $\begin{array}{l}\text { Negative association } \\
-\end{array}$ & $\begin{array}{l}\text { No association } \\
0\end{array}$ \\
\hline Feelings of control & 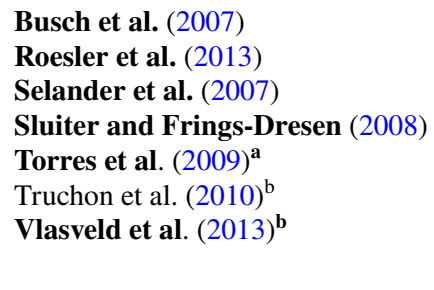 & & $\begin{array}{l}\text { Boot et al. (2008) } \\
\text { Ekberg et al. (2015) } \\
\text { Karoly et al. (2013) } \\
\text { Krause et al. (2013) } \\
\text { Murphy et al. (2011) } \\
\text { Richard et al. (2011) } \\
\text { Torres et al. (2009) } \\
\text { Volker et al. (2015) }\end{array}$ \\
\hline Perceived health & 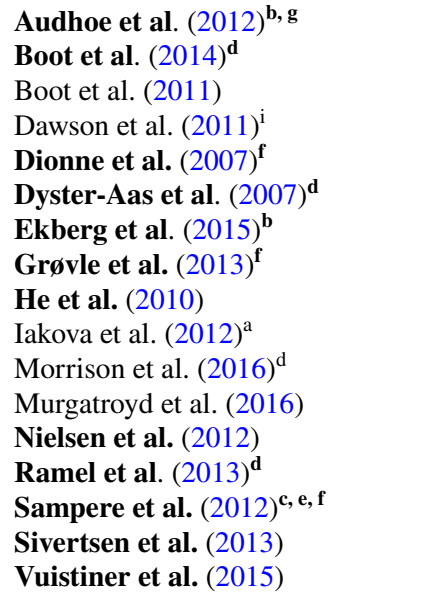 & & $\begin{array}{l}\text { Chen et al. (2012) } \\
\text { De Vries et al. }(2012 b)^{\mathbf{d}} \\
\text { Dionne et al. }(2007)^{\mathbf{f}} \\
\text { Elfving et al. }(2009)^{\mathbf{d}} \\
\text { Grøvle et al. }(2013)^{\mathbf{f}} \\
\text { Hansen et al. }(2009) \\
\text { Iakova et al. }(2012)^{\mathbf{a}} \\
\text { Jensen et al. }(2013) \\
\text { Lindell et al. }(2010) \\
\text { Richter et al. (2011) } \\
\text { Sampere et al. }(2012)^{\mathbf{c}, \mathbf{e}, \mathbf{f}}\end{array}$ \\
\hline
\end{tabular}

Bold indicates studies with a low risk of bias

${ }^{a}$ Depends on the form/subscale of the factor

${ }^{b}$ Not for every moment on which the outcome is measured

${ }^{c}$ Depends on the type of disorder of the participant

${ }^{\mathrm{d}}$ Outcomes from univariate analysis

${ }^{\mathrm{e}}$ Depends on the gender of the participant

${ }^{\mathrm{f}}$ Depends on the form of work participation

${ }^{g}$ Not for every moment on which the factor is measured

${ }^{\mathrm{h}}$ Depends on the country where the participant lives

${ }^{\mathrm{i} O u t c o m e s}$ from bivariate analysis

overall quality of evidence for the associations between the person-related factors optimism, catastrophizing, self-efficacy, coping strategies, fear-avoidance beliefs, feelings of control, and perceived work-relatedness of health problems and work participation was rated as low. The evidence for the association between motivation and work participation was rated as very low.

\section{Expectations regarding recovery or RTW}

In total, 32 quantitative studies investigated the association between expectations regarding recovery or RTW and work participation (Table 1: Audhoe et al. 2012; Besen et al. 2015; Boot et al. 2008; Busch et al. 2007; Carriere et al. 2015a, b; Carstens et al. 2014; Coggon et al. 2013; Cowan et al. 2012; Du Bois et al. 2009; Ekberg et al. 2015; Gross and Battié 2010; Hou et al. 2008, 2012; Iakova et al. 2012; Jensen et al.
2013; Johansson et al. 2010; Lindell et al. 2010; Magnussen et al. 2007b; Murgatroyd et al. 2016; Nieuwenhuijsen et al. 2013; Opsahl et al. 2016; Reme et al. 2009; Richter et al. 2011; Rönnberg et al. 2007; Sampere et al. 2012; Sluiter and Frings-Dresen 2008; Spector et al. 2012; Truchon et al. 2012; Turner et al. 2008; Vuistiner et al. 2015; Wåhlin et al. 2012). The majority of these studies found evidence of a positive association, which suggests that having positive expectations about one's recovery or chances of RTW has a positive effect on work participation for employees with health problems (Audhoe et al. 2012; Besen et al. 2015; Busch et al. 2007; Carriere et al. 2015a, b; Carstens et al. 2014; Cowan et al. 2012; Du Bois et al. 2009; Ekberg et al. 2015; Gross and Battié 2010; Hou et al. 2008, 2012; Jensen et al. 2013; Johansson et al. 2010; Lindell et al. 2010; Magnussen et al. 2007b; Murgatroyd et al. 2016; Opsahl et al. 2016; Reme et al. 2009; Richter et al. 2011; Rönnberg et al. 
Table 2 Results of multivariate analyses of quantitative studies with factors coping strategies, fear-avoidance, work-relatedness and catastrophizing

\begin{tabular}{|c|c|c|c|}
\hline Factor & $\begin{array}{l}\text { Positive association } \\
+\end{array}$ & $\begin{array}{l}\text { Negative association } \\
-\end{array}$ & $\begin{array}{l}\text { No association } \\
0\end{array}$ \\
\hline Coping strategies & $\begin{array}{l}\text { Huijs et al. }(2012)^{\mathbf{a}, \mathbf{c}} \\
\text { Karoly et al. (2013) } \\
\text { Øyeflaten et al. (2008) }\end{array}$ & $\begin{array}{l}\text { Arwert et al. }(2017)^{\mathbf{a}} \\
\text { Dawson et al. }(2011)^{\mathrm{a}} \\
\text { Grytten et al. }(2017)^{\mathrm{a}, \mathrm{g}} \\
\text { Iakova et al. }(2012) \\
\text { Karoly et al. }(2013)^{\mathrm{d}} \\
\text { Norlund et al. }(2011) \\
\text { Strober and Arnett }(2016)^{\mathrm{a}}\end{array}$ & $\begin{array}{l}\text { Arwert et al. }(2017)^{\mathbf{a}} \\
\text { Dawson et al. }(2011)^{\mathrm{a}, \mathrm{d}} \\
\text { De Vries et al. }(2012 \mathrm{~b}) \\
\text { Grytten et al. }(2017)^{\mathbf{a}, \mathbf{g}} \\
\text { Heymans et al. }(2009) \\
\text { Huijs et al. }(2012)^{\mathbf{a}, \mathbf{c}} \\
\text { Luk et al. }(2010)^{\mathbf{d}} \\
\text { Øyeflaten et al. }(2008)^{\mathbf{a}} \\
\text { Øyeflaten et al. (2016) } \\
\text { Strober and Arnett (2016) } \\
\text { Truchon et al. }(2010)\end{array}$ \\
\hline Fear-avoidance beliefs & & $\begin{array}{l}\text { Coggon et al. }(2013)^{\mathrm{i}} \\
\text { Dawson et al. }(2011)^{\mathrm{i}} \\
\text { De Vries et al. }(2012 \mathrm{~b})^{\mathrm{i}} \\
\text { Dionne et al. }(2007)^{\mathbf{e}, \mathbf{g}, \mathbf{i}, \mathbf{j}} \\
\text { Du Bois et al. }(2009)^{\mathbf{i}} \\
\text { Dyster-Aas et al. }(2007)^{\mathbf{d}, \mathbf{k}} \\
\text { Grøvle et al. }(2013)^{\mathbf{d}, \mathbf{g}, \mathbf{h}, \mathbf{i}} \\
\text { Heymans et al. }(2009)^{\mathbf{k}} \\
\text { Heymans et al. }(2007)^{\mathbf{k}} \\
\text { Kovacs et al. }(2007)^{\mathbf{j}, \mathbf{k}} \\
\text { Magnussen et al. }(2007 \mathbf{b})^{\mathbf{j}} \\
\text { Mannion et al. }(2009)^{\mathbf{j}} \\
\text { Morris and Watson }(2011)^{\mathbf{j}} \\
\text { Opsahl et al. }(2016)^{\mathbf{h}, \mathbf{j}} \\
\text { Øyeflaten et al. }(2008)^{\mathbf{j}} \\
\text { Øyeflaten et al. }(2016)^{\mathbf{j}} \\
\text { Truchon et al. }(2012)^{\mathbf{j}}\end{array}$ & 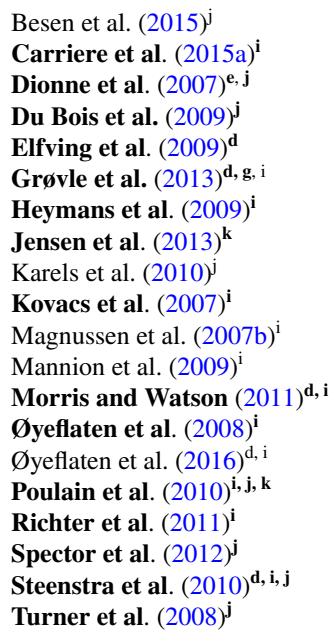 \\
\hline Perceived work-relatedness & & $\begin{array}{l}\text { Jensen et al. (2013) } \\
\text { Karels et al. (2010) } \\
\text { Kuijer et al. (2016) } \\
\text { Sampere et al. (2012) } \text { c, e }\end{array}$ & $\begin{array}{l}\text { Coggon et al. (2013) } \\
\text { Dawson et al. (2011) } \\
\text { Sampere et al. }(2012)^{\mathbf{c}, \mathbf{e}} \\
\text { Turner et al. }(2008)^{\mathbf{d}}\end{array}$ \\
\hline Catastrophizing & & $\begin{array}{l}\text { Adams et al. (2017) } \\
\text { Carriere et al. (2015a) } \\
\text { Cowan et al. }(2012)^{\mathbf{f}, \mathbf{g}} \\
\text { De Vries et al. (2012b) } \\
\text { Karoly et al. (2013) } \\
\text { Lindell et al. (2010) } \\
\text { Wijnhoven et al. (2007) }\end{array}$ & $\begin{array}{l}\text { Besen et al. (2015) } \\
\text { Cowan et al. (2012), } \mathbf{f} \\
\text { Dawson et al. (2011) } \\
\text { Karels et al. (2010) } \\
\text { Mannion et al. (2009) } \\
\text { Morris and Watson (2011) } \\
\text { Sarda et al. (2009) } \\
\text { Spector et al. (2012) } \\
\text { Turner et al. (2008) }\end{array}$ \\
\hline
\end{tabular}

Bold indicates studies with a low risk of bias

${ }^{a}$ Depends on the form/subscale of the factor

${ }^{b}$ Not for every moment on which the outcome is measured

${ }^{c}$ Depends on the type of disorder of the participant

${ }^{\mathrm{d}}$ Outcomes from univariate analysis

${ }^{\mathrm{e}}$ Depends on the gender of the participant

${ }^{\mathrm{f}}$ Depends on the job of the participant

${ }^{g}$ Depends on the form of work participation

h Outcomes from bivariate analysis

${ }^{\mathrm{i}}$ Fear-avoidance beliefs for movement/physical activity

${ }^{\mathrm{j}}$ Fear-avoidance beliefs for work

${ }^{\mathrm{k}}$ Total fear-avoidance 


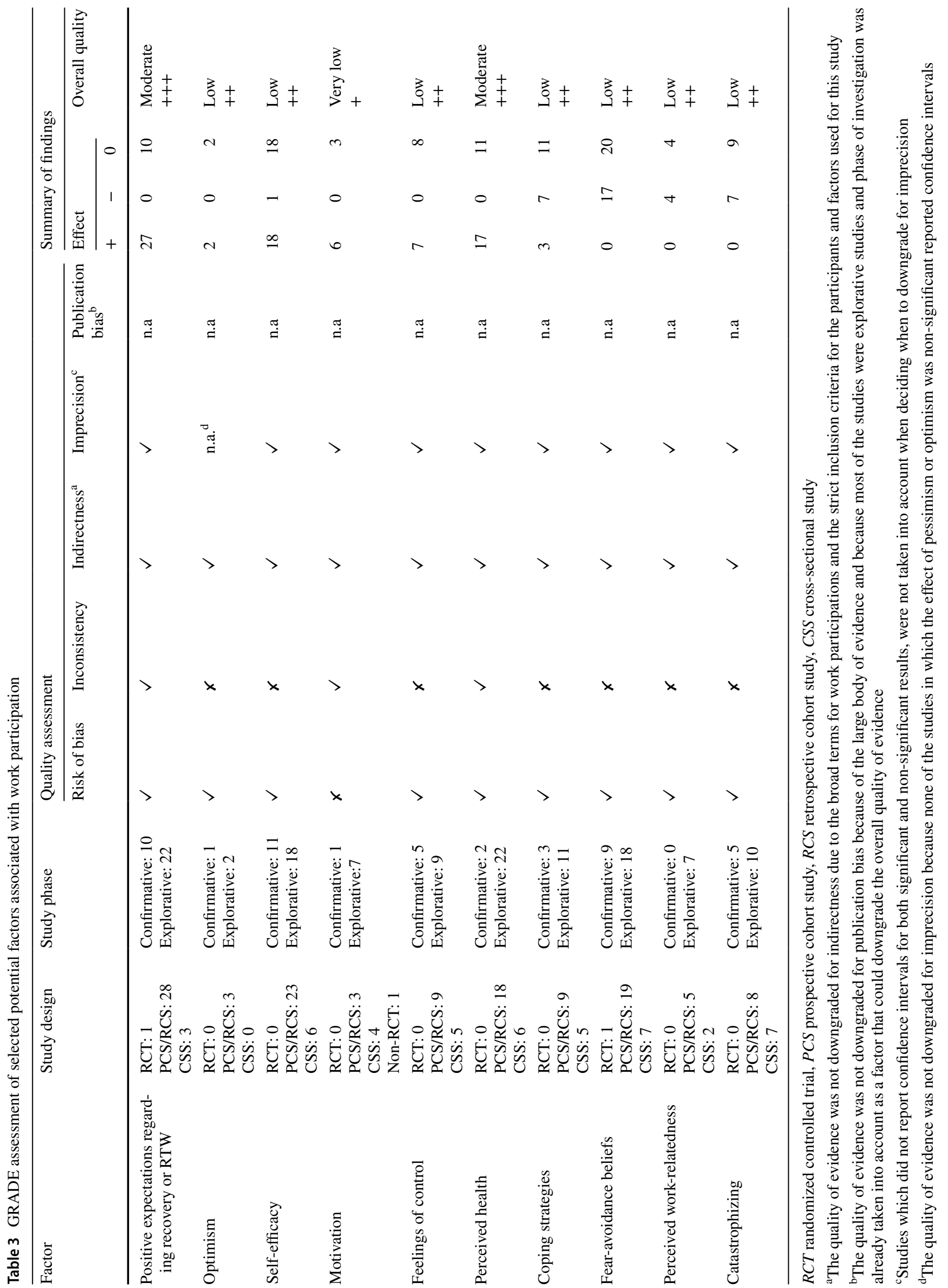


2007; Sampere et al. 2012; Sluiter and Frings-Dresen 2008; Spector et al. 2012; Truchon et al. 2012; Vuistiner et al. 2015; Wåhlin et al. 2012). However, some of these studies indicated that the effect was dependent on the subgroup of participants or the form of expectations (Ekberg et al. 2015; Gross and Battié 2010; Murgatroyd et al. 2016; Sluiter and Frings-Dresen 2008; Wåhlin et al. 2012). For example, in a study by Ekberg et al. (2015), positive recovery expectations were associated with early RTW, but RTW expectations were not. Only four studies did not find any association between expectations and work participation in multivariate analyses (Boot et al. 2008; Coggon et al. 2013; Iakova et al. 2012; Turner et al. 2008). There were no qualitative studies which suggested a positive association between these expectations and work participation. The overall quality of evidence for the effect of expectations regarding recovery or RTW on work participation was moderate. It was downgraded because all evidence came from explorative studies.

\section{Optimism}

Being optimistic or pessimistic was the least investigated person-related factor addressed in the studies found in this systematic review. Three quantitative studies investigated the influence of optimism or pessimism (Table 1: Hystad and Bye 2012; Lydell et al. 2011; Øyeflaten et al. 2008). One quantitative study reported a negative effect of pessimism on RTW, but did not find any effect of optimism (Hystad and Bye 2012). This was in contrast to a study by Øyeflaten et al. (2008) which reported that being pessimistic about oneself and the future had no significant effect on RTW, and to a study by Lydell et al. (2011), which found support for a positive effect of optimism on RTW. There were three qualitative studies in which it was mentioned that being optimistic was important for work participation (De Vries et al. 2011; Ellingsen and Aas 2009; Lundqvist and Samuelsson 2012). In summary, the majority of the studies suggest a positive association between optimism and work participation in employees with health problems. As most evidence came from explorative studies and because of inconsistency in study results, the overall quality of evidence was rated as low.

\section{Self-efficacy}

The association between self-efficacy and work participation was investigated in 29 quantitative studies (Table 1: Besen et al. 2015; Brouwer et al. 2009, 2010, 2015; D'Amato and Zijlstra 2010; De Vries et al. 2012b; Dionne et al. 2007; Ekberg et al. 2015; Healey et al. 2011; Huijs et al. 2012, 2017; Lagerveld et al. 2016; Mangels et al. 2011; Martins 2015; Murphy et al. 2011; Nieuwenhuijsen et al. 2013; O'Sullivan et al. 2012; Øyeflaten et al. 2008; Richard et al.
2011; Roesler et al. 2013; Sampere et al. 2012; Sarda et al. 2009; Shaw et al. 2011; Strauser et al. 2010; Stulemeijer et al. 2008; Volker et al. 2015; Waghorn et al. 2007; Wåhlin et al. 2012; Waynor et al. 2016). Eleven studies found a positive association between self-efficacy and work participation (Besen et al. 2015; De Vries et al. 2012b; Ekberg et al. 2015; Huijs et al. 2017; Lagerveld et al. 2016; Mangels et al. 2011; Martins 2015; Nieuwenhuijsen et al. 2013; Roesler et al. 2013; Shaw et al. 2011; Waghorn et al. 2007). Two studies found evidence of a positive association between self-efficacy and work participation for only some specific subgroups (Huijs et al. 2012; Sarda et al. 2009). The results of three other studies suggest that the association depends on the form of self-efficacy (Brouwer et al. 2015, 2009, 2010). In summary, the majority of the results suggest that having more self-efficacy is associated with more work participation in employees with health problems. Six qualitative studies supported these results (De Vries et al. 2011; Dunn et al. 2010; Hartke et al. 2011; Lundqvist and Samuelsson 2012; Magnussen et al. 2007a; Tamminga et al. 2012). However, some quantitative studies did not find evidence of an association between self-efficacy and work participation (D'Amato and Zijlstra 2010; Healey et al. 2011; Murphy et al. 2011; O'Sullivan et al. 2012; Øyeflaten et al. 2008; Sampere et al. 2012; Strauser et al. 2010; Stulemeijer et al. 2008; Volker et al. 2015; Wåhlin et al. 2012). One study even found a negative association between work-related social skills selfefficacy and current employment status (Waynor et al. 2016). As there was serious inconsistency in study results, the overall quality of evidence was downgraded to low.

\section{Motivation}

Of the eight quantitative studies which investigated the association between motivation and work participation (Table 1: Awang et al. 2016; Boyle et al. 2014; Braathen et al. 2007; Elving et al. 2009; Lydell et al. 2011; Puolakka et al. 2008; Saperstein et al. 2011; Wan Kasim et al. 2014), five found a positive association (Awang et al. 2016; Boyle et al. 2014; Braathen et al. 2007; Lydell et al. 2011; Saperstein et al. 2011). One additional quantitative study only found an influence of motivation for some forms of work participation (Puolakka et al. 2008). This study by Puolakka et al. (2008) indicated that motivation to work was associated with fewer days off work, but not with permanent work disability. Two studies with a low risk of bias did not find any association between motivation and work participation (Elfving et al. 2009; Wan Kasim et al. 2014). Seven qualitative studies addressed the possible positive influence of motivation, which suggests that employees with health problems who are motivated will have higher levels of work participation (Åhrberg et al. 2010; De Vries et al. 2011; Dekkers-Sánchez et al. 2010; Dunn et al. 2010; Hartke et al. 2011; Van Velzen 
et al. 2011; Wilbanks and Ivankova 2015). However, the overall quality of the quantitative evidence for this factor was downgraded to very low because evidence primarily came from explorative studies with serious risk of bias.

\section{Feelings of control}

There were 14 quantitative studies which addressed the possible positive association between feelings of control and work participation (Table 1: Boot et al. 2008; Busch et al. 2007; Ekberg et al. 2015; Karoly et al. 2013; Krause et al. 2013; Murphy et al. 2011; Richard et al. 2011; Roesler et al. 2013; Selander et al. 2007; Sluiter and Frings-Dresen 2008; Torres et al. 2009; Truchon et al. 2010; Vlasveld et al. 2013; Volker et al. 2015). The results of six studies indicated that the feeling of having more control is associated with more work participation (Busch et al. 2007; Roesler et al. 2013; Selander et al. 2007; Sluiter and Frings-Dresen 2008; Truchon et al. 2010; Vlasveld et al. 2013). These results were supported by one qualitative study by Dionne et al. (2013), in which it was reported that participants who did not RTW considered that their return depended more on factors related to their environment than on personal factors. However, one quantitative study only found evidence on some specific forms of control but not others (Torres et al. 2009). For example, in this study, having the feeling that one controls one's own pain was not associated with RTW, but believing that control of pain is a chance outcome decreased the likelihood of RTW (Torres et al. 2009). Seven studies found no evidence of an association between feelings of control and work participation at all (Boot et al. 2008; Ekberg et al. 2015; Karoly et al. 2013; Krause et al. 2013; Murphy et al. 2011; Richard et al. 2011; Volker et al. 2015). The overall quality of evidence derived from this review was low and was downgraded for serious inconsistency.

\section{Perceived health}

Twenty-four quantitative studies addressed the possible influence of perceived health on work participation (Table 1: Audhoe et al. 2012; Boot et al. 2011, 2014; Chen et al. 2012; Dawson et al. 2011; De Vries et al. 2012b; Dionne et al. 2007; Dyster-Aas et al. 2007; Ekberg et al. 2015; Elfving et al. 2009; Grøvle et al. 2013; Hansen et al. 2009; He et al. 2010; Iakova et al. 2012; Jensen et al. 2013; Lindell et al. 2010; Morrison et al. 2016; Murgatroyd et al. 2016; Nielsen et al. 2012; Ramel et al. 2013; Richter et al. 2011; Sampere et al. 2012; Sivertsen et al. 2013; Vuistiner et al. 2015). Seven studies found no association at all between the factor and work participation (Chen et al. 2012; De Vries et al. 2012b; Elfving et al. 2009; Hansen et al. 2009; Jensen et al. 2013; Lindell et al. 2010; Richter et al. 2011). However, the majority of the studies found that being positive about one's general health was positively associated with work participation (Audhoe et al. 2012; Boot et al. 2011, 2014; Dawson et al. 2011; Dionne et al. 2007; Dyster-Aas et al. 2007; Ekberg et al. 2015; He et al. 2010; Morrison et al. 2016; Murgatroyd et al. 2016; Nielsen et al. 2012; Ramel et al. 2013; Sivertsen et al. 2013; Vuistiner et al. 2015). There were three studies in which the results indicated that this association was dependent on the form of work participation (Dionne et al. 2007; Grøvle et al. 2013; Sampere et al. 2012). For example, the results of the study by Grøvle et al. (2013) suggested that perceived health was positively associated with the likelihood of RTW, but not with number of days until sustained RTW. The results of a study by Iakova et al. (2012) indicated that improvement in general health was associated with a higher likelihood of RTW, but general health at baseline and physical health were not. There were no qualitative studies which addressed the association between perceived health and work participation. The quality of evidence was rated as moderate.

\section{Coping strategies}

In total, 14 quantitative studies investigated the association between different coping strategies and work participation (Table 2: Arwert et al. 2017; Dawson et al. 2011; De Vries et al. 2012b; Grytten et al. 2017; Heymans et al. 2009; Huijs et al. 2012; Iakova et al. 2012; Karoly et al. 2013; Luk et al. 2010; Norlund et al. 2011; Øyeflaten et al. 2008, 2016; Strober and Arnett 2016; Truchon et al. 2010). Nine studies found an effect of some coping strategies (Arwert et al. 2017; Dawson et al. 2011; Grytten et al. 2017; Huijs et al. 2012; Iakova et al. 2012; Karoly et al. 2013; Norlund et al. 2011; Øyeflaten et al. 2008; Strober and Arnett 2016). The results of these studies indicated that some coping strategies, such as active problem-solving (Huijs et al. 2012), could increase the chance of work participation in sick employees, while other coping strategies, such as passive coping (Dawson et al. 2011) and avoidance coping (Iakova et al. 2012), could decrease the chance of work participation. However, five of the quantitative studies did not find any evidence of the effect of coping strategies (De Vries et al. 2012b; Heymans et al. 2009; Luk et al. 2010; Øyeflaten et al. 2016; Truchon et al. 2010). Six qualitative studies addressed the importance of different coping strategies for work participation (Becker et al. 2007; Dekkers-Sánchez et al. 2010; De Vries et al. 2011; Hartke et al. 2011; Lundqvist and Samuelsson 2012; Tamminga et al. 2012). The overall quality of evidence derived from this review was downgraded to low because most of the studies were explorative and because of serious inconsistency in study results. 


\section{Fear-avoidance beliefs}

In total, 27 studies addressed the possible association between fear-avoidance beliefs and work participation (Table 2: Besen et al. 2015; Carriere et al. 2015a; Coggon et al. 2013; Dawson et al. 2011; De Vries et al. 2012b; Dionne et al. 2007; Du Bois et al. 2009; Dyster-Aas et al. 2007; Elfving et al. 2009; Grøvle et al. 2013; Heymans et al. 2007, 2009; Jensen et al. 2013; Karels et al. 2010; Kovacs et al. 2007; Magnussen et al. 2007b; Mannion et al. 2009; Morris and Watson 2011; Opsahl et al. 2016; $\varnothing$ yeflaten et al. 2008, 2016; Poulain et al. 2010; Richter et al. 2011; Spector et al. 2012; Steenstra et al. 2010; Truchon et al. 2012; Turner et al. 2008). Most of the studies made a distinction between fear-avoidance beliefs for movement or physical activity and fear-avoidance beliefs for work. Six studies did find an association between fear-avoidance beliefs for work and work participation, but did not find an association between fear-avoidance beliefs for physical activity or movement and work participation (Kovacs et al. 2007; Magnussen et al. 2007b; Mannion et al. 2009; Morris and Watson 2011; Øyeflaten et al. 2008, 2016). However, Du Bois et al. (2009) reported that fear-avoidance beliefs for movement, rather than fearavoidance beliefs for work were associated with a higher chance of not returning to work. Three studies which only studied fear-avoidance for movement or physical activity found negative associations between this factor and work participation (Coggon et al. 2013; Dawson et al. 2011; De Vries et al. 2012b). Two studies which only investigated the association between fear-avoidance for work and work participation, also found negative associations (Opsahl et al. 2016; Truchon et al. 2012). Three studies found a negative association between general fear-avoidance and work participation (Dyster-Aas et al. 2007; Heymans et al. 2007, 2009). Studies by Dionne et al. (2007) and Grøvle et al. (2013) indicated that the effect of fear-avoidance was dependent on how work participation is measured. For example, the results of the study by Grøvle et al. (2013) suggested that fear-avoidance for movement is associated with the likelihood of RTW within two years, but not with number of days until sustained RTW. Ten studies did not find any association between fear-avoidance beliefs and work participation (Besen et al. 2015; Carriere et al. 2015a; Elfving et al. 2009; Jensen et al. 2013; Karels et al. 2010; Poulain et al. 2010; Richter et al. 2011; Spector et al. 2012; Steenstra et al. 2010; Turner et al. 2008). There were no qualitative studies which addressed this association. However, overall, the majority of the studies which investigated fear-avoidance beliefs, found a negative association between fear-avoidance and work participation. Because most of these studies were explorative and because there was serious inconsistency in study results, the overall quality of evidence was downgraded to low.

\section{Perceived work-relatedness}

Of the limited number of studies that addressed the relationship between perceiving the health problem as work-related and work participation, three studies did not find any association between this factor and work participation (Coggon et al. 2013; Dawson et al. 2011; Turner et al. 2008), while three studies found a negative association (Table 2: Jensen et al. 2013; Karels et al. 2010; Kuijer et al. 2016). These latter studies suggest that perceiving the health problem as work-related has a negative association with work participation in employees with health problems. Findings from an additional study, by Sampere et al. (2012), supported this negative association, but only for women and only for employees with mental disorders. There were no qualitative studies which addressed this association. As all of the studies which investigated this association were explorative and because there was serious inconsistency, the overall quality of evidence was downgraded to low.

\section{Catastrophizing}

Fifteen quantitative studies examined the association between catastrophizing and work participation (Table 2: Adams et al. 2017; Besen et al. 2015; Carriere et al. 2015a; Cowan et al. 2012; Dawson et al. 2011; De Vries et al. 2012b; Karels et al. 2010; Karoly et al. 2013; Lindell et al. 2010; Mannion et al. 2009; Morris and Watson 2011; Sarda et al. 2009; Spector et al. 2012; Turner et al. 2008; Wijnhoven et al. 2007). Eight quantitative studies in this review did not find an effect of catastrophizing on work status or sickness absence (Besen et al. 2015; Dawson et al. 2011; Karels et al. 2010; Mannion et al. 2009; Morris and Watson 2011; Sarda et al. 2009; Spector et al. 2012; Turner et al. 2008). No qualitative studies reported the negative influence of catastrophizing on work participation. However, six quantitative studies (Adams et al. 2017; Carriere et al. 2015a; De Vries et al. 2012b; Karoly et al. 2013; Lindell et al. 2010; Wijnhoven et al. 2007), including four studies with a low risk of bias (Adams et al. 2017; Carriere et al. 2015a; De Vries et al. 2012b; Lindell et al. 2010), found a negative association between catastrophizing and work participation. One quantitative study found a negative association between catastrophizing and return to modified work for some subgroups (Cowan et al. 2012). The evidence suggests that catastrophizing is negatively associated with work participation. Because most of the evidence came from explorative studies and because there was serious inconsistency, its overall quality was downgraded to low. 


\section{Discussion}

This systematic review of 113 studies identified the association between ten selected person-related factors and work participation of employees with health problems. The factors positively associated with work participation were positive expectations regarding recovery or RTW, optimism, self-efficacy, motivation, feelings of control, and perceived health. The factors negatively associated with work participation were fear-avoidance beliefs, perceived work-relatedness of the health problem and catastrophizing. Coping strategies had both positive and negative associations with work participation.

The synthesis of evidence showed that we can be moderately confident that positive expectations regarding recovery or RTW and better self-perceived health lead to a higher level of work participation in employees with health problems. This possible association between these expectations and work participation is in line with the findings of a review by Iles et al. (2009), in which recovery expectations in employees with low back pain were a strong predictor of work outcome. Our finding on the association between selfperceived health and work participation is supported by the results of a review by Lidal et al. (2007), in which poor state of health was one of the most frequent self-reported barriers to employment in employees with spinal cord injury.

For the person-related factors optimism, catastrophizing, self-efficacy, coping strategies, fear-avoidance beliefs, feelings of control, and perceived work-relatedness of health problems, the quality of evidence for an association with work participation was rather low. Nevertheless, the results of this review suggest that fear-avoidance beliefs, perceived work-relatedness of health problems and catastrophizing are negatively associated with work participation. Optimism, self-efficacy and feelings of control seem to lead to more work participation. According to the results of our review, different coping strategies can have a positive or a negative effect on work participation.

The results of our review of these factors are consistent with the results of a Delphi study by Peters et al. (2017), which indicate that researchers and clinicians in the field of work disability or RTW identify most of these factors (catastrophizing, self-efficacy, coping strategies, fear-avoidance beliefs and feelings of control) as affecting work participation. However, the results of the current review partly stand in contrast to the results of a review by De Vries et al. (2012a), in which catastrophizing had no association with remaining at work for employees at all. However, that review only included three cross-sectional studies on employees with chronic non-specific musculoskeletal pain, including two of low quality, which might explain this contradictory finding.
Studies conducted by Achterberg et al. (2012) and Peters et al. (2017) found that insurance physicians and experts identified motivation as the most important person-related factor for work participation. The results of the qualitative studies included in the current review are in line with this (Åhrberg et al. 2010; De Vries et al. 2011; Dekkers-Sánchez et al. 2010; Dunn et al. 2010; Hartke et al. 2011; Van Velzen et al. 2011; Wilbanks and Ivankova 2015). Surprisingly, the current review found a very low quality of quantitative evidence for an association between motivation and work participation. The results of a review by Faber et al. (2016) indicate that motivation consists of seven underlying aspects, including intrinsic motivation, expectations and self-efficacy. If researchers choose to study individual aspects of motivation rather than overall motivation, this could explain why we did not find many studies addressing the association between overall motivation and work participation. Moreover, when researchers choose to study the effects of factors such as self-efficacy and expectations alongside motivation, the overall effect of motivation could be underestimated due to the association with these other factors. These reasons could explain why we found very low evidence for an association between motivation and work participation.

\section{Strengths and limitations of the current review}

This systematic review studied the association between a set of selected person-related factors and work participation and was not limited to specific diseases or disorders; this makes the results of this study generalizable to various health problems. A key methodological strength of this review is that the articles were screened and assessed by multiple independent reviewers, explicitly to avoid bias. In addition, the quality of the studies as assessed by the assessment tools of the Joanna Briggs Institute (2014), was considered when interpreting the results of this review. The benefit of using these tools is that, although they are adapted to different study designs, the criteria on which the risk of bias is assessed are comparable between the different tools. A final strength of our study is that when assessing the level of evidence for possible associations, we used the GRADE framework for prognostic factor research (Huguet et al. 2013) to prevent errors in judgement.

Despite methodological strengths, there were also some constraints in the methodology of our review. We included 113 studies which had different ways of defining and measuring the person-related factors, which raises uncertainties in the interpretation of our findings. Besides, we included studies with participants with different diseases and disorders and participants with different occupations. At first sight, the diversity in participants improves the generalizability of our findings. However, it is possible that the influence of some of the studied factors on work participation differs 
across participants with different diseases and disorders or differs across occupations, which may also raise uncertainties in the interpretation of our findings. Moreover, due to heterogeneity of measurements of factors and outcomes, and heterogeneity in the statistical analyses performed in these studies, it was not possible to perform a meta-analysis. Furthermore, not every study controlled for the same variables in their analysis, and therefore there may have been hidden variables which may have influenced the outcomes.

\section{Implications for practice and future research}

We suggest that in addition to health-related factors and environmental factors, person-related factors should be considered by occupational physicians and insurance physicians when they diagnose, evaluate or provide treatment to employees. In particular, the factors perceived health and expectations regarding recovery or RTW may have significant influence on work participation and, therefore, they should be considered by occupational and insurance physicians in their efforts to improve work participation of employees with health problems.

Although the results of this review suggest that personrelated factors are associated with work participation, the quality of evidence for the involvement of some of these factors was low or very low. Therefore, more research is needed to improve the quality of evidence for the involvement of these factors. Future research should also focus on how physicians might gain more insight into these different cognitions and perceptions of employees. This might assist in the identification of barriers to RTW or barriers to remaining at work for employees with health problems. Finally, research will be needed to determine whether the use of information about person-related factors by physicians improves work participation of employees with health problems and leads to a better quality of care.

Funding This study was funded by Instituut Gak (Grant number: 2016-757).

\section{Compliance with ethical standards}

Conflict of interest The authors declare that they have no conflict of interest.

Open Access This article is distributed under the terms of the Creative Commons Attribution 4.0 International License (http://creativeco mmons.org/licenses/by/4.0/), which permits unrestricted use, distribution, and reproduction in any medium, provided you give appropriate credit to the original author(s) and the source, provide a link to the Creative Commons license, and indicate if changes were made.

\section{References}

Achterberg TJ, Wind H, Frings-Dresen MHW (2012) What are the most important factors for work participation in the young disabled? An expert view. Disabil Rehabil 34:1519-1525

Adams H, Thibault P, Ellis T et al (2017) The relation between catastrophizing and occupational disability in individuals with major depression: concurrent and prospective associations. J Occup Rehabil 27:405-412

Åhrberg Y, Landstad BJ, Bergroth A et al (2010) Longing and vanity: emotions behind successful return to work for women on longterm sick leave. Work J Prev Assess Rehabil 37:167-177

Arwert HJ, Schults M, Meesters JJL et al (2017) Return to work 2-5 years after stroke: a cross sectional study in a hospital-based population. J Occup Rehabil 27:239-246

Audhoe SS, Hoving JL, Nieuwenhuijsen K et al (2012) Prognostic factors for the work participation of sick-listed unemployed and temporary agency workers with psychological problems. J Occup Rehabil 22:437-446

Awang H, Shahabudin SM, Mansor N (2016) Return-to-work program for injured workers: factors of successful return to employment. Asia Pac J Public Health 28:694-702

Becker D, Whitley R, Bailey EL et al (2007) Long-term employment trajectories among participants with severe mental illness in supported employment. Psychiatr Serv 58:922-928

Besen E, Young AE, Shaw WS (2015) Returning to work following low back pain: towards a model of individual psychosocial factors. J Occup Rehabil 25:25-37

Blank L, Peters J, Pickvance S et al (2008) A systematic review of the factors which predict return to work for people suffering episodes of poor mental health. J Occup Rehabil 18:27-34

Boot CRL, Heijmans M, van der Gulden JWJ et al (2008) The role of illness perceptions in labor participation of the chronically ill. Int Arch Occup Environ Health 82:13-20

Boot CRL, Koppes LLJ, van den Bossche SNJ et al (2011) Relation between perceived health and sick leave in employees with a chronic illness. J Occup Rehabil 21:211-219

Boot CRL, Hogg-Johnson S, Bültmann U et al (2014) Differences in predictors for return to work following musculoskeletal injury between workers with and without somatic comorbidities. Int Arch Occup Environ Health 87:871-879

Boyle CL, Nott MT, Baguley IJ et al (2014) Contextual influences on employment of people with dual diagnosis: spinal cord injury and traumatic brain injury. Aust Occup Ther J 61:335-343

Braathen TN, Veiersted KB, Heggenes J (2007) Improved work ability and return to work following vocational multidisciplinary rehabilitation of subjects on long-term sick leave. J Rehabil Med 39:493-499

Brouwer S, Krol B, Reneman MF et al (2009) Behavioral determinants as predictors of return to work after long-term sickness absence: an application of the theory of planned behavior. J Occup Rehabil 19:166-174

Brouwer S, Reneman MF, Bültmann U et al (2010) A prospective study of return to work across health conditions: perceived work attitude, self-efficacy and perceived social support. J Occup Rehabil 20:104-112

Brouwer S, Amick BC, Lee H et al (2015) The predictive validity of the return-to-work self-efficacy scale for return-to-work outcomes in claimants with musculoskeletal disorders. J Occup Rehabil 25:725-732

Bryngelson A (2009) Long-term sickness absence and social exclusion. Scand J Public Health 37:839-845

Busch H, Goransson S, Melin B (2007) Self-efficacy beliefs predict sustained long-term sick absenteeism in individuals with chronic musculoskeletal pain. Pain Pract 7:234-240 
Carriere JS, Thibault P, Milioto M et al (2015a) Expectancies mediate the relations among pain catastrophizing, fear of movement, and return to work outcomes after whiplash injury. J Pain 16:1280-1287

Carriere JS, Thibault P, Sullivan MJL (2015b) The mediating role of recovery expectancies on the relation between depression and return-to-work. J Occup Rehabil 25:348-356

Carstens JKP, Shaw WS, Boersma K et al (2014) When the wind goes out of the sail-declining recovery expectations in the first weeks of back pain. Eur J Pain 18:269-278

Chen YH, Lin HT, Lin YT et al (2012) Self-perceived health and return to work following work-related hand injury. Occup Med (Lond) 62:295-297

Clay FJ, Newstead SV, McClure RJ (2010) A systematic review of early prognostic factors for return to work following acute orthopaedic trauma. Injury 41:787-803

Coggon D, Ntani G, Vargas-Prada S et al (2013) International variation in absence from work attributed to musculoskeletal illness: findings from the CUPID study. Occup Environ Med 70:575-584

Cowan J, Makanji H, Mudgal C et al (2012) Determinants of return to work after carpal tunnel release. J Hand Surg Am 37:18-27

D'Amato A, Zijlstra F (2010) Toward a climate for work resumption: the nonmedical determinants of return to work. J Occup Environ Med 52:67-80

Dawson AP, Schluter PJ, Hodges PW et al (2011) Fear of movement, passive coping, manual handling, and severe or radiating pain increase the likelihood of sick leave due to low back pain. Pain 152:1517-1524

De Vries HJ, Brouwer S, Groothoff JW et al (2011) Staying at work with chronic nonspecific musculoskeletal pain: a qualitative study of workers' experiences. BMC Musculoskelet Disord $12: 126$

De Vries HJ, Reneman MF, Groothoff JW et al (2012a) Factors promoting staying at work in people with chronic nonspecific musculoskeletal pain: a systematic review. Disabil Rehabil 34:443-458

De Vries HJ, Reneman MF, Groothoff JW et al (2012b) Workers who stay at work despite chronic nonspecific musculoskeletal pain: do they differ from workers with sick leave? J Occup Rehabil 22:489-502

Dekkers-Sánchez PM, Wind H, Sluiter JK et al (2010) A qualitative study of perpetuating factors for long term sick leave and promoting factors for return to work: chronic work disabled patients in their own words. J Rehabil Med 42:544-552

Dekkers-Sánchez PM, Wind H, Sluiter JK et al (2013) What factors are most relevant to the assessment of work ability of employees on long-term sick leave? The physicians' perspective. Int Arch Occup Environ Health 86:509-518

Denis DJ (2015) Applied univariate, bivariate, and multivariate statistics. Wiley, New Jersey

Dionne CE, Bourbonnais R, Frémont P et al (2007) Determinants of "return to work in good health" among workers with back pain who consult in primary care settings: a 2-year prospective study. Eur Spine J 16:641-655

Dionne CE, Bourbonnais R, Frémont P et al (2013) Obstacles to and facilitators of return to work after work-disabling back pain: the workers' perspective. J Occup Rehabil 23:280-289

Du Bois M, Szpalski M, Donceel P (2009) Patients at risk for long-term sick leave because of low back pain. Spine J 9:350-359

Dunn EC, Wewiorski NJ, Rogers ES (2010) A qualitative investigation of individual and contextual factors associated with vocational recovery among people with serious mental illness. Am J Orthopsychiatry 80:185-194

Dyster-Aas J, Kildal M, Willebrand M (2007) Return to work and health-related quality of life after burn injury. J Rehabil Med 39:49-55
Ekberg K, Wåhlin C, Persson J et al (2015) Early and late return to work after sick leave: predictors in a cohort of sick-listed individuals with common mental disorders. J Occup Rehabil 25:627-637

Elfving B, Asell M, Ropponen A et al (2009) What factors predict full or partial return to work among sickness absentees with spinal pain participating in rehabilitation? Disabil Rehabil 31:1318-1327

Ellingsen KL, Aas RW (2009) Work participation after acquired brain injury: experiences of inhibiting and facilitating factors. Int $\mathbf{J}$ Disabil Manag Res 4:1-11

Faber BJM, Wind H, Frings-Dresen MHW (2016) An interview guide for clinicians to identify a young disabled person's motivation to work. Work 54:577-590

Gross DP, Battié MC (2010) Recovery expectations predict recovery in workers with back pain but not other musculoskeletal conditions. J Spinal Disord Tech 23:451-456

Grøvle L, Haugen AJ, Keller A et al (2013) Prognostic factors for return to work in patients with sciatica. Spine J 13:1849-1857

Grytten N, Skår ABR, Aarseth JH et al (2017) The influence of coping styles on long-term employment in multiple sclerosis: a prospective study. Mult Scler 23:1008-1017

Hansen TB, Dalsgaard J, Meldgaard A et al (2009) A prospective study of prognostic factors for duration of sick leave after endoscopic carpal tunnel release. BMC Musculoskelet Disord 10:144

Hartke RJ, Trierweiler R, Bode R (2011) Critical factors related to return to work after stroke: a qualitative study. Top Stroke Rehabil 18:341-351

$\mathrm{He} \mathrm{Y}, \mathrm{Hu}$ J, Yu ITS et al (2010) Determinants of return to work after occupational injury. J Occup Rehabil 20:378-386

Healey EL, Haywood KL, Jordan KP et al (2011) Impact of ankylosing spondylitis on work in patients across the UK. Scand J Rheumatol 40:34-40

Heymans MW, Ford JJ, McMeeken JM et al (2007) Exploring the contribution of patient-reported and clinician based variables for the prediction of low back work status. J Occup Rehabil 17:383-397

Heymans MW, Anema JR, van Buuren S et al (2009) Return to work in a cohort of low back pain patients: development and validation of a clinical prediction rule. J Occup Rehabil 19:155-165

Hou WH, Tsauo JY, Lin CH et al (2008) Worker's compensation and return-to-work following orthopaedic injury to extremities. J Rehabil Med 40:440-445

Hou WH, Sheu CF, Liang HW et al (2012) Trajectories and predictors of return to work after traumatic limb injury-a 2-year follow-up study. Scand J Work Environ Health 38:456-466

Huguet A, Hayden JA, Stinson J et al (2013) Judging the quality of evidence in reviews of prognostic factor research: adapting the GRADE framework. Syst Rev 2:71

Huijs JJJM., Koppes LLJ, Taris TW et al (2012) Differences in predictors of return to work among long-term sick-listed employees with different self-reported reasons for sick leave. J Occup Rehabil 22:301-311

Huijs JJJM., Koppes LLJ, Taris TW et al (2017) Work characteristics and return to work in long-term sick-listed employees with depressive symptoms. J Occup Rehabil 19:116-174

Hystad SW, Bye HH (2012) Dispositional pessimism but not optimism is related to sickness absence caused by musculoskeletal symptoms. Pers Individ Dif 52:207-212

Iakova M, Ballabeni P, Erhart P et al (2012) Self perceptions as predictors for return to work 2 years after rehabilitation in orthopedic trauma inpatients. J Occup Rehabil 22:532-540

Iles RA, Davidson M, Taylor NF (2008) A systematic review of psychosocial predictors of failure to return to work in non-chronic non-specific low back pain. Occup Environ Med 65:507-517

Iles RA, Davidson M, Taylor NF et al (2009) Systematic review of the ability of recovery expectations to predict outcomes in 
non-chronic non-specific low back pain. J Occup Rehabil 19:25-40

Jensen OK, Stengaard-Pedersen K, Jensen C et al (2013) Prediction model for unsuccessful return to work after hospital-based intervention in low back pain patients. BMC Musculoskelet Disord 14:140

Joanna Briggs Institute (2014) Joanna Briggs Institute reviewers' manual, 2014 edn. Joanna Briggs Institute, Adelaide

Johansson AC, Linton SJ, Rosenblad A et al (2010) A prospective study of cognitive behavioural factors as predictors of pain, disability and quality of life one year after lumbar disc surgery. Disabil Rehabil 32:521-529

Karels CH, Bierma-Zeinstra SM, Verhagen AP et al (2010) Sickness absence in patients with arm, neck and shoulder complaints presenting in physical therapy practice: 6 months follow-up. Man Ther 15:476-481

Karoly P, Ruehlman LS, Okun MA (2013) Psychosocial and demographic correlates of employment vs disability status in a national community sample of adults with chronic pain: toward a psychology of pain presenteeism. Pain Med 14:1698-1707

Kovacs FM, Muriel A, Castillo Sánchez MD et al (2007) Fear avoidance beliefs influence duration of sick leave in Spanish low back pain patients. Spine (Phila Pa 1976) 32:1761-1766

Krause I, Kern S, Horntrich A et al (2013) Employment status in multiple sclerosis: impact of disease-specific and non-diseasespecific factors. Mult Scler 19:1792-1799

Kuijer PPFM., Kievit AJ, Pahlplatz TMJ et al (2016) Which patients do not return to work after total knee arthroplasty? Rheumatol Int 36:1249-1254

Lagerveld SE, Brenninkmeijer V, Blonk RWB et al (2016) Predictive value of work-related self-efficacy change on RTW for employees with common mental disorders. Occup Environ Med 0:1-3

Lidal IB, Huynh TK, Biering-Sørensen F (2007) Return to work following spinal cord injury: a review. Disabil Rehabil 29:1341-1375

Lindell O, Johansson SE, Strender LE (2010) Predictors of stable return-to-work in non-acute, non-specific spinal pain: low total prior sick-listing, high self prediction and young age. A twoyear prospective cohort study. BMC Fam Pract 11:53

Luk KDK, Wan TWM, Wong YW et al (2010) A multidisciplinary rehabilitation programme for patients with chronic low back pain: a prospective study. J Orthop Surg (Hong Kong) 18:131-138

Lundqvist A, Samuelsson K (2012) Return to work after acquired brain injury: a patient perspective. Brain Inj 26:1574-1585

Lydell M, Hildingh C, Månsson J et al (2011) Thoughts and feelings of future working life as a predictor of return to work: a combined qualitative and quantitative study of sick-listed persons with musculoskeletal disorders. Disabil Rehabil 33:1262-1271

Magnussen L, Nilsen S, Råheim M (2007a) Barriers against returning to work - as perceived by disability pensioners with back pain: a focus group based qualitative study. Disabil Rehabil 29:191-197

Magnussen L, Strand LI, Skouen JS et al (2007b) Motivating disability pensioners with back pain to return to work-a randomized controlled trial. J Rehabil Med 39:81-87

Mangels M, Schwarz S, Worringen U et al (2011) Long sick leave after orthopaedic inpatient rehabilitation: treatment failure or relapse? Int J Rehabil Res 34:29-37

Mannion AF, Horisberger B, Eisenring C et al (2009) The association between beliefs about low back pain and work presenteeism. J Occup Environ Med 51:1256-1266

Martins AC (2015) Using the International Classification of Functioning, Disability and Health (ICF) to address facilitators and barriers to participation at work. Work J Prev Assess Rehabil 50:585-593
Moher D, Liberati A, Tetzlaff J et al (2009) Preferred reporting items for systematic reviews and meta-analyses: the PRISMA statement. PLoS Med 6:e1000097

Morris J, Watson PJ (2011) Investigating decisions to absent from work with low back pain: a study combining patient and GP factors. Eur J Pain 15:278-285

Morrison EJ, Ehlers SL, Bronars CA et al (2016) Employment status as an indicator of recovery and function one year after hematopoietic stem cell transplantation. Biol Blood Marrow Transpl 22:1690-1695

Murgatroyd DF, Harris IA, Tran Y et al (2016) Predictors of return to work following motor vehicle related orthopaedic trauma. BMC Musculoskelet Disord 17:171

Murphy GC, Middleton J, Quirk R et al (2011) Predicting employment status at 2 years' postdischarge from spinal cord injury rehabilitation. Rehabil Psychol 56:251-256

Nielsen MBD, Bültmann U, Madsen IEH et al (2012) Health, work, and personal-related predictors of time to return to work among employees with mental health problems. Disabil Rehabil 34:1311-1316

Nieuwenhuijsen K, Noordik E, van Dijk FJH et al (2013) Return to work perceptions and actual return to work in workers with common mental disorders. J Occup Rehabil 23:290-299

Norlund S, Reuterwall C, Höög J et al (2011) Work related factors and sick leave after rehabilitation in burnout patients: experiences from the REST-project. J Occup Rehabil 21:23-30

O'Sullivan D, Strauser DR, Wong AW (2012) Five-factor model of personality, work behavior self-efficacy, and length of prior employment for individuals with disabilities: an exploratory analysis. Rehabil Couns Bull 55:156-165

Opsahl J, Eriksen HR, Tveito TH (2016) Do expectancies of return to work and Job satisfaction predict actual return to work in workers with long lasting LBP? BMC Musculoskelet Disord 17:481

Øyeflaten I, Hysing M, Eriksen HR (2008) Prognostic factors associated with return to work following multidisciplinary vocational rehabilitation. J Rehabil Med 40:548-554

Øyeflaten I, Opsahl J, Eriksen HR et al (2016) Subjective health complaints, functional ability, fear avoidance beliefs, and days on sickness benefits after work rehabilitation-a mediation model. BMC Musculoskelet Disord 17:225

Peters SE, Johnston V, Ross M et al (2017) Expert consensus on facilitators and barriers to return-to-work following surgery for nontraumatic upper extremity conditions: a Delphi study. J Hand Surg Eur Vol 42:127-136

Poulain C, Kernéis S, Rozenberg S et al (2010) Long-term return to work after a functional restoration program for chronic low-back pain patients: a prospective study. Eur Spine J 19:1153-1161

Puolakka K, Ylinen J, Neva MH et al (2008) Risk factors for back pain-related loss of working time after surgery for lumbar disc herniation: a 5-year follow-up study. Eur Spine J 17:386-392

Ramel E, Rosberg HE, Dahlin LB et al (2013) Return to work after a serious hand injury. Work 44:459-469

Reilly R, Evans K, Gomersall J et al (2016) Effectiveness, cost effectiveness, acceptability and implementation barriers/enablers of chronic kidney disease management programs for Indigenous people in Australia, New Zealand and Canada: a systematic review of mixed evidence. BMC Health Serv Res 16:119

Reme SE, Hagen EM, Eriksen HR (2009) Expectations, perceptions, and physiotherapy predict prolonged sick leave in subacute low back pain. BMC Musculoskelet Disord 10:139

Richard S, Dionne CE, Nouwen A (2011) Self-efficacy and health locus of control: relationship to occupational disability among workers with back pain. J Occup Rehabil 21:421-430

Richter JM, Blatter BM, Heinrich J et al (2011) Prognostic factors for disability claim duration due to musculoskeletal symptoms among self-employed persons. BMC Public Health 11:945 
Roesler ML, Glendon AI, O'Callaghan FV (2013) Recovering from traumatic occupational hand injury following surgery: a biopsychosocial perspective. J Occup Rehabil 23:536-546

Rönnberg K, Lind B, Zoëga B et al (2007) Patients' satisfaction with provided care/information and expectations on clinical outcome after lumbar disc herniation surgery. Spine (Phila Pa 1976) 32:256-261

Sampere M, Gimeno D, Serra C et al (2012) Return to work expectations of workers on long-term non-work-related sick leave. J Occup Rehabil 22:15-26

Saperstein AM, Fiszdon JM, Bell MD (2011) Intrinsic motivation as a predictor of work outcome after vocational rehabilitation in schizophrenia. J Nerv Ment Dis 199:672-677

Sarda J, Nicholas MK, Asghari A et al (2009) The contribution of selfefficacy and depression to disability and work status in chronic pain patients: a comparison between Australian and Brazilian samples. Eur J Pain 13:189-195

Selander J, Marnetoft SU, Åsell M (2007) Predictors for successful vocational rehabilitation for clients with back pain problems. Disabil Rehabil 29:215-220

Shaw WS, Reme SE, Linton SJ et al (2011) 3rd place, PREMUS best paper competition: development of the return-to-work self-efficacy (RTWSE-19) questionnaire-psychometric properties and predictive validity. Scand J Work Environ Health 37:109-119

Sieurin L, Josephson M, Vingård E (2009) Positive and negative consequences of sick leave for the individual, with special focus on part-time sick leave. Scand J Public Health 37:50-56

Sivertsen H, Lillefjell M, Espnes GA (2013) The relationship between health promoting resources and work participation in a sample reporting musculoskeletal pain from the Nord-Trøndelag Health Study, HUNT 3, Norway. BMC Musculoskelet Disord 14:100

Sluiter JK, Frings-Dresen MHW (2008) Quality of life and illness perception in working and sick-listed chronic RSI patients. Int Arch Occup Environ Health 81:495-501

Spector JT, Turner JA, Fulton-Kehoe D et al (2012) Pre-surgery disability compensation predicts long-term disability among workers with carpal tunnel syndrome. Am J Ind Med 55:816-832

Steenstra IA, Ibrahim SA, Franche RL et al (2010) Validation of a risk factor-based intervention strategy model using data from the readiness for return to work cohort study. J Occup Rehabil 20:394-405

Strauser DR, O'Sullivan D, Wong AW (2010) The relationship between contextual work behaviours self-efficacy and work personality: an exploratory analysis. Disabil Rehabil 32:1999-2008

Strober L, Arnett P (2016) Unemployment among women with multiple sclerosis: the role of coping and perceived stress and support in the workplace. Psychol Health Med 21:496-504

Stulemeijer M, van der Werf S, Borm GF et al (2008) Early prediction of favourable recovery 6 months after mild traumatic brain injury. J Neurol Neurosurg Psychiatry 79:936-942

Tamminga SJ, de Boer AGEM., Verbeek JHAM. et al (2012) Breast cancer survivors' views of factors that influence the return-towork process - a qualitative study. Scand J Work Environ Health 38:144-154

Torres X, Collado A, Arias A et al (2009) Pain locus of control predicts return to work among Spanish fibromyalgia patients after completion of a multidisciplinary pain program. Gen Hosp Psychiatry 31:137-145

Truchon M, Côté D, Schmouth ME et al (2010) Validation of an adaptation of the stress process model for predicting low back pain related long-term disability outcomes: a cohort study. Spine (Phila Pa 1976) 35:1307-1315

Truchon M, Schmouth ME, Côté D et al (2012) Absenteeism screening questionnaire (ASQ): a new tool for predicting long-term absenteeism among workers with low back pain. J Occup Rehabil 22:27-50

Turner JA, Franklin G, Fulton-Kehoe D et al (2008) ISSLS prize winner: early predictors of chronic work disability: a prospective, population-based study of workers with back injuries. Spine (Phila Pa 1976) 33:2809-2818

Van Velzen JM, van Bennekom CAM, Edelaar MJA et al (2009) Prognostic factors of return to work after acquired brain injury: a systematic review. Brain Inj 23:385-395

Van Velzen JM, van Bennekom CAM, van Dormolen M et al (2011) Factors influencing return to work experienced by people with acquired brain injury: a qualitative research study. Disabil Rehabil 33:2237-2246

Verbeek JH (2006) How can doctors help their patients to return to work? PLoS Med 3:e88

Vingård E, Alexanderson K, Norlund A (2004) Chap. 9. Consequences of being on sick leave. Scand J Public Health 32:207-215

Vlasveld MC, van der Feltz-Cornelis CM, Anema JR et al (2013) The associations between personality characteristics and absenteeism: A cross-sectional study in workers with and without depressive and anxiety disorders. J Occup Rehabil 23:309-317

Volker D, Zijlstra-Vlasveld MC, Brouwers EPM et al (2015) Returnto-work self-efficacy and actual return to work among long-term sick-listed employees. J Occup Rehabil 25:423-431

Vooijs M, Leensen MCJ, Hoving JL et al (2015) Disease-generic factors of work participation of workers with a chronic disease: a systematic review. Int Arch Occup Environ Health 88:1015-1029

Vuistiner P, Luthi F, Erhart P et al (2015) Subjective perceptions as prognostic factors of time to fitness for work during a 4-year period after inpatient rehabilitation for orthopaedic trauma. Swiss Med Wkly 145:w14235

Waghorn GR, Chant DC, King R (2007) Work-related subjective experiences, work-related self-efficacy, and career learning among people with psychiatric disabilities. Am J Psychiatr Rehabil 10:275-300

Wåhlin C, Ekberg K, Persson J et al (2012) Association between clinical and work-related interventions and return-to-work for patients with musculoskeletal or mental disorders. J Rehabil Med 44:355-362

Wan Kasim SH, Midin M, Abu Bakar AK et al (2014) Employment program for patients with severe mental illness in Malaysia: a 3-month outcome. Compr Psychiatry 55:S38-45

Waynor WR, Gill KJ, Gao N (2016) The role of work related selfefficacy in supported employment for people living with serious mental illnesses. Psychiatr Rehabil J 39:62-67

Wijnhoven HAH, de Vet HCW, Picavet HSJ (2007) Sex differences in consequences of musculoskeletal pain. Spine (Phila Pa 1976) $32: 1360-1367$

Wilbanks SR, Ivankova NV (2015) Exploring factors facilitating adults with spinal cord injury rejoining the workforce: a pilot study. Disabil Rehabil 37:739-749

World Health Organization (2001) International Classification of Functioning, Disability and Health: ICF. Geneva, Switzerland 